\section{Unethical aspects of homeopathic dentistry}

D. Shaw ${ }^{1}$

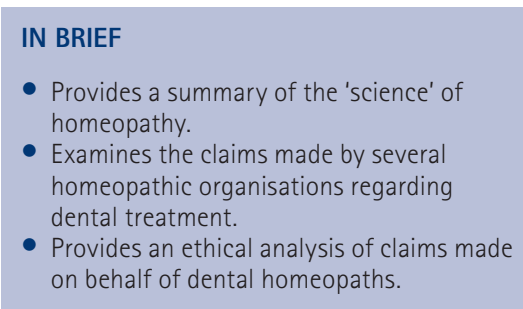

In the last year there has been a great deal of public debate about homeopathy, the system of alternative medicine whose main principles are that like cures like and that potency increases relative to dilution. The House of Commons Select Committee on Science and Technology concluded in November 2009 that there is no evidence base for homeopathy, and agreed with some academic commentators that homeopathy should not be funded by the NHS. ${ }^{1,2}$ While homeopathic doctors and hospitals are quite commonplace, some might be surprised to learn that there are also many homeopathic dentists practising in the UK. This paper examines the statements made by several organisations on behalf of homeopathic dentistry and suggests that they are not entirely ethical and may be in breach of various professional guidelines.

\section{THE 'SCIENCE' OF HOMEOPATHY}

Homeopathy is sometimes mistakenly believed to be simply another form of complementary medicine similar to herbalism, acupuncture or chiropractic. In fact, homeopathy is even less mainstream than these alternative approaches. We shall see in the course of this paper that there is no high-quality evidence that homeopathy is effective, but a more basic problem with homeopathy is that its basic principles have no basis in logic or science.

The main principles of homeopathy are that like cures like and that potency increases relative to dilution. The Society of Homeopaths explains the first of these principles as follows: 'a substance that would cause symptoms in a healthy person is used to cure those same symptoms in illness. For example, one remedy which might be used in a person suffering from insomnia is coffea, a remedy made from coffee. ${ }^{3}$ In other words, homeopathic coffee cures rather than causes insomnia. This is obviously rather counterintuitive, as it

'Lecturer in Ethics, Dental School, Faculty of Medicine, University of Glasgow, 378 Sauchiehall Street, Glasgow, G2 3JZ

Correspondence to: Dr David Shaw

Email:david.shaw@.glasgow.ac.uk

Refereed Paper

Accepted 7 October 2010

DOI: 10.1038/sj.bdj.2010.1032

${ }^{\circledR}$ British Dental Journal 2010; 209: 493-496 would be somewhat unusual for a substance to cause an illness outside homeopathy but to cure it within homeopathy. The explanation for this strange principle is provided by the second principle: it is because the homeopathic remedy is extremely dilute that it is able to cure a condition it would normally cause, as it 'triggers the body's natural system of healing. This is also extremely counterintuitive, and the Society of Homeopaths admits that 'Scientifically it can not yet be explained precisely how homeopathy works. ${ }^{3}$ As we shall see, it is far from clear that homeopathy works at all.

\section{HOMEOPATHIC ORGANISATIONS}

A number of organisations represent homeopaths in the UK. The most prominent is the British Homeopathic Association (BHA), which 'exists to promote homeopathy practised by doctors and other healthcare professionals' and lobbies for the provision of homeopathy on the NHS. ${ }^{4}$ In addition, there is the aforementioned Society of Homeopaths (SoH), which provides registration for professional homeopaths and has its own Code of Ethics and Practice. ${ }^{5}$ There is also a third organisation, the Faculty of Homeopaths (FoH), which promotes 'academic and scientific development of homeopathy and ensures the highest standards in the education, training and practice of homeopathy.'
In terms of dentistry, the only British organisation is the British Homeopathic Dental Association (BHDA), which aims 'to promote the use of homeopathy within the dental profession and to advance the professional understanding of the subject." (The BHDA recommends that patients should try to find dentists who have completed training run by the FoH.)

\section{British Homeopathic Association}

What does each of these organisations have to say about homeopathic dentistry? The Society of Homeopaths says nothing specific, which is unsurprising as it exists only to register dentists and provide a Code. The BHA website has a link to a twopage document explaining dental homeopathy, which states that "patients find that a number of dental conditions respond well to homeopathic treatment, including pain, swelling, bruising, dental anxiety, nausea, tooth sensitivity, jaw cramping, teething in babies, neuralgia, toothache, bleeding, infection, ulcers and cold sores. ${ }^{8}$ While this list is long, this is actually quite a circumspect claim: it is not stated that 'evidence shows that homeopathic dentistry works', but that 'patients find' that it works - and any such finding could be due to a placebo effect. In the past, the BHA has made stronger claims about homeopathy, but has learned from experience that such claims are often challenged. The BHA 
website also provides a list of homeopathic dentists and refers patients to the BHDA for further information.

In addition to the aforementioned document, the BHA website also features two articles on dental homeopathy. One is from 2001, and claims that 'Several clinical trials and observational studies have demonstrated the therapeutic effects of Arnica in the reduction of post-extraction complications', but it has since been shown that this evidence was nothing of the sort, and the trials were poorly designed..$^{9}$ Given that the science has moved on, it is somewhat unethical of the BHA to have such an outdated and misleading claim on their website. The same article also states that 'Homeopathy when used in the dental setting is a safe and effective form of treatment which is often requested and sought by the general public.' Homeopathic treatment may not directly harm the patient, but if it fails and she must then seek conventional treatment to stop her pain or bleeding, then she has been harmed and the treatment was not truly safe. We must also ask what is meant by 'effective' in this context; placebos can be effective, and so too can homeopathic remedies if this is all that is meant by the word, but the minimum standard for evidence-based medicine (and dentistry) is more effective than placebo - and it is far from clear that this is true of homeopathy.

A much more recent publication on the BHA website explains common dental ailments and potential homeopathic remedies. ${ }^{10}$ Its author states that 'Homeopathically-trained dentists are much more than drillers, fillers and billers. We can even hope to improve the overall health of the patient and not just the dental condition presented to us.' One would have thought that the same is also true of the vast majority of conventionally trained dentists. He also recommends that 'You should always go to a dentist if the pain is severe and preferably one who can also prescribe or recommend homeopathy', the implication being that a homeopathic dentist will be better able to treat the pain. The author goes on to explain the top five reasons people visit the dentist, and suggests homeopathic 'medicines' for each one. The use of this word instead of 'remedies' is not unproblematic, as 'medicines' is usually used to describe substances with a recognised pharmacological content and effect, while homeopathic remedies normally have neither. For toothache, he recommends belladonna and pulsatilla. For abscesses, 30C belladonna is also a good choice, but for "chronic (recurring) abscesses then Hepar sulph should help, in the 6C potency if the abscesses are pus-filled, although you should always visit a dentist if the condition is severe.' The fact that the abscesses might be recurring because of the lack of efficacy of extremely dilute nightshade is not mentioned. The author also mentions arsenicum album for gum disease (without specifying whether he means gingivitis or periodontitis), arnica for broken teeth and extractions, and nitricum acidum for ulcers. The article ends with an endorsement of non-fluoride toothpaste, and the suggestion that 'some people believe the peppermint in conventional toothpastes antidotes homeopathic medicines. Advising people to use toothpaste without fluoride is bad enough, but suggesting that normal toothpaste interferes with homeopathic remedies is an assertion for which there is no evidence whatsoever. Such suggestions risk harm to people's oral health and are deeply unethical.

\section{Faculty of Homeopathy}

Considering that it seeks to maintain the highest standards of practice in homeopathy, it is somewhat surprising that the Faculty has no ethical code or practice guidelines on its website. What it does have is a copy of its Dental Guidelines for 2010, which recommend dental homeopathy for 'common core applications; acute anticipatory anxiety; acute dental fear both in adults and children; post-operative pain; post extraction/trauma; haemorrhage; toothache; pericoronitis; teething; dental abscess; dry socket; [and] dental collapse.' ${ }^{11}$ What should these conditions be treated with? To take two examples from this list, the guidelines state that haemorrhage should be treated with china officinalis, and a dental abscess should be treated with hepar sulphurus calcareum. The former is a Peruvian tree bark, and the latter is oyster shell and sulphur. But of course, given that these are homeopathic remedies, these substances will be very dilute. The FoH guideline does not suggest a particular dilution, but hepar is available online in dilutions ranging from $3 \mathrm{C}$ to $30 \mathrm{C}$ (diluted) to $200 \mathrm{C}$. A $2 \mathrm{C}$ dilution takes the original substance and dilutes it to one part in 100, and then repeats the dilution again, so that there is now one part in 10,000 of the original substance. $3 \mathrm{C}$ therefore equals one part per million. At 12C, no molecules of the original substance remain; by comparison, the US water supply is allowed to have arsenic present at up to $4 \mathrm{C} .{ }^{12}$ As already mentioned, homeopaths claim that the potency of such medications increases with dilution, even beyond the point at which no molecules are left, and that the water 'remembers' the substance that it has diluted.

Of course, the fact that dentists are treating patients with 'substances' that have none of their original molecules present should be considered along with the fact that, even were there molecules remaining, there is no good evidence that any of these treatments actually work. Is training dentists to treat patients with these 'remedies' really maintaining the best standards of treatment, as the Faculty claims? Apart from anything else, it is misleading patients to claim that they are being treated with a substance when none of its molecules are actually present. (This strange feature of homeopathy explains why it is possible to obtain homeopathic plutonium.) Note also that all the "treatments' in the BHA section of this paper were of similar extreme dilutions.

\section{British Homeopathic Dental Association}

The BHDA's website is reminiscent of the BHA's several years ago. In contrast to the more modest claims made by the BHA, the SoH and the FoH, the BHDA makes very strong claims for dental homeopathy. The homepage of the BHDA website welcomes visitors with a question, which is answered with another question:

'Why should you visit a Homeopathic dentist?

Do you think that your present dentist is really kind and caring?

Homeopathy is a very caring discipline. Try a member of the BHDA, and experience a really kind, considerate, holistic and caring approach to dental treatment. ${ }^{{ }^{13}}$

The obvious implication is that your current dentist is not really kind, caring and considerate. Homeopathy may well be a caring discipline, but it is rather 
disrespectful to the profession to suggest that non-homeopathic dentists are somehow inferior in terms of the care that they provide. Ben Goldacre has pointed out that 'a routine feature of homeopaths' marketing practices is to denigrate mainstream medicine', ${ }^{14}$ and this seems to be another example. Another page of the BHDA's website offers six reasons to visit a homeopathic dentist:

1. 'Because they treat patients holistically

2. Homeopathic remedies are effective and have no unpleasant side effects

3. There are remedies which stop swelling and pain after injections and extractions

4. There are remedies which reduce the pain and swelling of dental abscesses

5. There are remedies which alleviate toothache

6. There are remedies which which [sic] cure ulcers and cold sores and many more [sic]. ${ }^{15}$

It is not clear why the first is really a reason to visit a homeopathic dentist, as many mainstream dentists adopt a holistic approach. But the main problem is the second claim. As stated above, it is misleading to claim that homeopathic remedies are 'effective'; homeopaths claim that there is in fact a great deal of evidence that homeopathy is more effective than placebo, but all of this 'evidence' is flawed in one way or another, often through failure to properly randomise or blind trials. ${ }^{14}$

Where is the evidence that homeopathic remedies can stop swelling and pain, alleviate toothache, and cure ulcers and cold sores? (Note that the swelling and pain claims are also made by the BHA and $\mathrm{FoH}$ websites.) No references are provided, presumably for the simple reason that there is no such evidence. Such remedies may perhaps have a placebo effect that reduces swelling and pain (and patients might get better naturally without even a placebo effect), but that is not the same as 'stopping' symptoms, which implies a direct physical effect.

The World Health Organisation recently warned against using homeopathy to treat serious diseases; ${ }^{16}$ while dental abscesses are not as serious as malaria or HIV, they can lead to complications if not treated properly. Furthermore, there exists no drug that can cure the herpes simplex virus, the cause of cold sores; while conventional medicine can treat sores and make them disappear, there is always a risk that they will return. Offering patients the hope of a cure when none is available is extremely unethical. (It is unclear what the "many more' cures offered by the sixth reason are supposed to be.) The websites of the BHA and the $\mathrm{FoH}$ are also guilty of misleading the public to some extent with their claims, even if they do not make claims of cure.

\section{RESPECTING THE GUIDELINES?}

Quite apart from the fact that some of the claims on the BHDA's website are misleading and unethical, they may also fall foul of the rules set out by both the Society of Homeopaths ( $\mathrm{SoH})$ and the Advertising Standards Authority (ASA). Section 48 of the Code of Practice and Ethics of the SoH lists nine principles that must be adhered to in advertising; the first three are:

- 'Advertising shall not contain claims of superiority.

- No advertising may be used which expressly or implicitly claims to cure named diseases.

- Advertising shall not be false, fraudulent, misleading, deceptive, extravagant or sensational. ${ }^{17}$

As we have already seen, the BHDA's website certainly claims by implication that homeopathic dentists are more caring and holistic than mainstream dentists, which seems to be an assertion of superiority. Cold sores are not technically a named disease, but the BHDA's claim that homeopathy can cure them would seem to be in contravention of at least the spirit of this principle. The SoH code also states that the Advertising Standards Authority's Code of Practice must be adhered to; one of its principles states that "No marketing communication should mislead, or be likely to mislead, by inaccuracy, ambiguity, exaggeration, omission or otherwise. ${ }^{18}$ The BHDA's website is clearly promoting homeopathic dentistry through ambiguity, and as such may also fall foul of the ASA's rules. A similar case could be made regarding the BHA and FoH websites, but they make substantially weaker claims.

Finally, it appears possible that homeopathic dentists in general are also in contravention of the General Dental Council's
(GDC's) Standards for Dental Professionals, which state that dentists must 'provide $a$ good standard of care based on available up-to-date evidence and reliable guidance.. [and] justify the trust that your patients, the public and your colleagues have in you by always acting honestly and fairly. ${ }^{19}$ We have seen that the websites of the BHA, $\mathrm{FoH}$ and BHDA are not entirely honest, and as already mentioned, the evidence indicates that homeopathy is not effective. Furthermore, for the placebo effect to occur, patients must believe that they are receiving treatment that is better than placebo - in other words, they must be deceived even in order to obtain the paltry benefit that homeopathy might offer. ${ }^{20}$ The principle of respect for autonomy and the requirements of valid consent mandate honesty and transparency when dealing with patients, but a small element of deception is essential for homeopathy to work at all. In this sense, ethical homeopathic practice is virtually impossible, although prescribing simple placebos ethically may be possible in some situations. ${ }^{21}$

\section{CONCLUSION}

This paper has pointed out some problems with homeopathic 'science', highlighted misleading and unethical aspects of the websites of the BHA, the $\mathrm{FoH}$ and the BHDA, and suggested that the latter may be in breach of the codes of the Society of Homeopaths and the Advertising Standards Authority. It appears possible that any homeopathic dentist is engaging in unethical practice to some extent and may be in breach of GDC guidelines. One of the principles of the SoH (section 11 of the Code of Ethics and Practice) states that 'Homeopaths report research findings and clinical experience methodically, honestly and without distortion. All speculative theories will be stated as such and clearly distinguished. ${ }^{17}$ Any implication that homeopathy is effective beyond a placebo effect is speculative, but the various homeopathy documents mentioned in this paper do not clearly indicate that this is the case. Many patients actively seek homeopathic treatment, but any information they are provided with should be honest and impartial; many of the claims currently being made by some homeopathic organisations are unethical and damaging to the profession of dentistry. 
1. O'Dowd A. Giving homeopathy on the NHS is unethical and unreliable, MPs are told. Br Med J 2009; 339: b5080.

2. Shaw D. Homeopathy is where the harm is. J Med Ethics 2010; 36: 130-131.

3. Society of Homeopaths. What is homeopathy? http:// www.homeopathy-soh.org/about-homeopathyl what-is-homeopathy/. Accessed 22 October 2010.

4. British Homeopathic Association. About us. http:// www.britishhomeopathic.org/about_us/. Accessed 22 October 2010.

5. Society of Homeopaths. About the society. Code of Ethics and Practice. http://www.homeopathy soh.org/about-the-society/code-of-ethics.aspx. Accessed 22 October 2010.

6. Faculty of Homeopathy. About us. http://www. facultyofhomeopathy.org/about_us/. Accessed 22 October 2010

7. British Homeopathic Dental Association. About us. http://www.bhda.co.uk/aboutbhda.php. Accessed 22 October 2010

8. British Homeopathic Association. Homeopathy and dental care: your guide to treatment. http:// www.britishhomeopathic.org/export/sites/bha_site/
how_we_can_help/advice_sheets/Dental_care.pdf. Accessed 22 October 2010.

9. Darby P. Dental homeopathy - an accidental introduction. http://www.britishhomeopathic.org/export/ sites/bha_site/hh_article_bank/conditions_a_to_e/ spring_2001.3_dental_homeopathy.pdf. Accessed 22 October 2010

10. Wander P. Introduction to homeopathy series: Top 5 reasons we visit the dentist. http://www.britishhomeopathic.org/export/sites/bha_site/hh_article bank/ conditions_a_to_e/Jan 10_Homeopathic_dentistry. pdf. Accessed 22 October 2010.

11. Faculty of Homeopathy. Dental Guidelines 2010. http://www.facultyofhomeopathy.org/export/ sites/faculty_site/exams/guidelines/Dental_guidelines_2010.pdf. Accessed 22 October 2010.

12. Environmental Protection Agency. Arsenic in drinking water. http://water.epa.gov/lawsregs/rulesregs/ sdwa/arsenic/index.cfm. Accessed 22 October 2010

13. British Homeopathic Dental Association. Homepage. http://www.bhda.co.uk/. Accessed 22 October 2010.

14. Goldacre B. Benefits and risks of homeopathy. Lancet 2007; 370: 1672-1673.

15. British Homeopathic Dental Association. Why should you visit a homeopathic dentist? http://www.bhda.co.uk/why.php. Accessed 22 October 2010.

16. Mastha $\mathrm{O}$. WHO warns against using homoeopathy to treat serious diseases. Br Med J 2009; 339: 63447.

17. Society of Homeopaths. Code of Ethics and Practice. http://www.homeopathy-soh.org/aboutthe-society/documents/CodeofEthicsApr04.pdf. Accessed 22 October 2010.

18. Advertising Standards Authority Committee of Advertising Practice. The CAP code. 11th ed. http:// cap.org.uk/The-Codes/ /media/Files/CAP/Codes/ CAPCode.ashx. Accessed 22 October 2010.

19. General Dental Council. Standards for dental professionals. http://www.gdc-uk.org/ NR/rdonlyres/FFD61DA5-A09E-4B38-8FFBBA342E9F0AF4/16687/147158_Standards_Profs2. pdf. Accessed 22 October 2010.

20. Ernst E. Harmless homeopathy? Int J Clin Rheumatol 2009; 4: 7-10.

21. Shaw D. Prescribing placebos ethically: the appeal of negatively informed consent. J Med Ethics 2009; 35: 97-99. 